\title{
Tingkat Kepuasan Mahasiswa Terhadap Kualitas Pelayanan Universitas Sam Ratulangi Menggunakan Analisis Faktor
}

\author{
Ivenly Lombone ${ }^{a}$, Marline S. Paendonga, Yohanes Langia \\ aJurusan Matematika, FMIPA, Unsrat, Manado
}

K A T A K UN C I

Analisis Faktor Eksploratori

Kepuasan Mahasiswa

Jasa dan Pelayanan

\begin{tabular}{l}
\hline K E Y W O R D S \\
\hline Exploratory factor analysis \\
Student satisfaction \\
Distinction and servic
\end{tabular}

\begin{abstract}
A B S T R A K
Penelitian dilakukan untuk mengetahui tingkat kepuasan mahasiswa terhadap kualitas pelayanan Universitas Sam Ratulangi (UNSRAT), mencari faktor-faktor penentu kepuasan dan faktor yang bersifat dominan terhadap kualitas pelayanan UNSRAT dan mencari indikator-indikator penyusun faktor dominan tersebut. Data diperoleh dengan membagikan kuesioner kepada mahasiswa di 11 fakultas UNSRAT pada bulan Mei-Juni 2012 sebagai responden. Jumlah sampel yang diambil berjumlah 391 mahasiswa. Data dianalisis menggunakan Analisis Deskriptif dan Analisis Faktor untuk memperoleh gambaran tentang faktor-faktor yang mempengaruhi kepuasan mahasiswa terhadap pelayanan Universitas Sam Ratulangi. Hasil penelitian menunjukkan bahwa mahasiswa cukup puas dengan pelayanan yang diberikan oleh UNSRAT dengan faktor dominan yang menentukan kepuasan mahasiswa adalah kepastian.

\begin{tabular}{l}
\hline A B S T R A C T \\
The study was conducted to determine the level of student \\
satisfaction towards service quality Universitas Sam Ratulangi (UNSRAT), \\
seeking the determinants of satisfaction and that is the dominant factor to \\
service quality and look UNSRAT indicators making up the dominant \\
factor. Data obtained by distributing questionnaires to students in 11 \\
faculties UNSRAT in May-June 2012 as the respondent. The number of \\
samples taken totaled 391 students. Data were analyzed using descriptive \\
analysis and factor analysis to obtain a description of the factors that \\
affect student satisfaction with the services of Sam Ratulangi University. \\
The results showed that students were quite satisfied with the services \\
provided by UNSRAT the dominant factors that determine student \\
satisfaction is a assurance.
\end{tabular}
\end{abstract}

sebagai konsumen. Kepuasan mahasiswa harus menjadi dasar dari keputusan manajemen, sehingga perguruan tinggi harus menjadikan peningkatan kepuasan mahasiswa sebagai suatu sasaran yang mendasar.

Analisis faktor adalah teknik untuk mengidentifikasi variabel atau faktor yang memiliki pola hubungan tertentu dalam sebuah kelompok variabel (Pidekso, 2009). Dengan demikian, dengan analisis faktor kita dapat mengetahui tingkat kepuasan mahasiswa terhadap kualitas pelayanan Universitas Sam Ratulangi. Sehingga melalui penelitian ini diharapkan memberikan masukkan kepada para pimpinan, dosen dan karyawan usaha bidang pendidikan masa kini, para pimpinan, dosen, dan karyawan harus memperhatikan kepuasan pelanggan dari sudut pandang mahasiswa 
mengenai faktor-faktor yang mempengaruhi kepuasan mahasiswa.

\section{Metode}

Penelitian ini menggunakan data primer melalui kuesioner yang berisi indikator-indikator pelayanan yang diperoleh mahasiswa selama menjadi mahasiswa UNSRAT. Kuesioner ini dibagikan langsung pada mahasiswa yang merupakan sampel dimasing-masing fakultas. Selanjutnya penerapan analisis faktor sesuai langkah-langkah yang ditetapkan sebelumnya. Variabel-variabel yang digunakan adalah sebagai berikut :

X1: Semua pelayanan kepada mahasiswa di lakukan tepat waktu

X2: Karyawan selalu dapat di temui pada jam kerja

X3: Pelayanan pembayaran SPP di lakukan dengan baik

X4: Pemberian KHS di lakukan tepat waktu

X5: Rentan waktu pengisian KRS sudah cukup

X6: Fakultas anda memiliki bagian administrasi yang cermat dan kooperatif

X7: Dosen selalu tepat waktu bila ada janji bertemu dengan mahasiswa

x8: Dosen selalu hadir tepat waktu pada saat memberikan materi kuliah

X9: $\quad$ Dosen selalu hadir dalam memberikan kuliah

X10: Dosen selalu memberikan absensi kehadiran pada saat proses perkuliahan

X11: Karyawan memberikan informasi dengan jelas dan terinci tentang pelayanan yang akan di berikan

X12: Seluruh karyawan bersedia membantu kesulitan yang di hadapi oleh mahasiswa

X13: Seluruh karyawan bersedia meluangkan waktu untuk menanggapi permintaan mahasiswa dengan cepat

X14: Dosen siap membantu jika ada mahasiswa yang kesulitan dalam suatu mata kuliah

X15: Dosen PA anda selalu siap membantu anda

X16: Karyawan sopan dalam melayani mahasiswa

X17: Karyawan menguasai informasi seputar pelayanan mahasiswa

X18: Dosen selalu memberikan mata kuliah dengan jelas dan mudah di pahami oleh mahasiswa

X18: Dosen menguasai meteri yang di berikan saat proses perkuliahan

X20: Dosen selalu memberikan tugas dan mengembalikannya

X21: Materi UTS dan UAS berkaitan dengan materi yang sudah anda dapatkan pada saat perkuliahan

X22: Seluruh karyawan dengan senang hati dan sabar melayani kebutuhan mahasiswa

X23: Bagian administrasi memiliki jam kerja yang sesuai dengan kebutuhan mahasiswa

X24: Perpustakaan memiliki jam kerja yang sesuai dengan kebutuhan mahasiwa

X25: Dosen selalu mengutamakan kepentingan mahasiswa

X26: Fakultas anda sudah menggunakan teknologi dalam proses pembelajaran dan layanan
X27: Gedung atau bangunan fakultas anda sudah memadai

X28: Ruang belajar yang dimiliki Fakultas anda telah memadai

X29: Fasilitas parkir yang dimiliki fakultas anda telah memadai

X30: Fasilitas perpustakaan lengkap

X31: Ruang perpustakaan tertata rapi

X32: Ketersediaan Lab sesuai kebutuhan perkuliahan

X33: Kebersihan ruang kuliah

X34: Gedung ORMAWA sudah memadai

X35: Fasilitas olahraga lengkap

\section{Results and Discussion}

\subsection{Umum Responden}

Populasi yang dijadikan objek penelitian adalah mahasiswa program S1 UNSRAT yang berjumlah 17053 mahasiswa. Jumlah sampel ini terdiri dari 11 fakultas, untuk itu agar dapat mewakilinya digunakan rumus proporsi. Karakteristik responden dapat diketahui melalui analisis berdasarkan tahun masuk (angkatan), jalur masuk, umur dan jenis kelamin. Responden dalam penelitian ini adalah mahasiswa UNSRAT yang aktif dari tahun 2008-2011.

\subsection{Uji Validitas dan Reliabilitas}

Semua item pertanyaan yang diajukan kepada responden adalah valid karena memenuhi syarat r_hit>r_tabel yang menurut tabel $r$ (product moment) untuk derajat bebas ( $n-2)$ sebesar 98 dan alpha sebesar 0,05 bernilai 0,197 (Ghozali, 2006). Pada penelitian ini dengan juga ukuran sampel sebanyak 100 responden diperoleh nilai cronbach alpha 0,958 maka setiap item atau instrumen dalam penelitian ini layak digunakan karena telah memenuhi kriteria

\subsection{Analisis Faktor}

\section{Uji KMO Dan Bartlett}

Dari Tabel $1 \mathrm{KMO}$ dan bartlett's test ternyata hasilnya menunjukkan bahwa nilai Kaiser-Meyer-Olkin Measure of Sampling Adequacy adalah sebesar 0,927 yang artinya ada korelasi yang cukup signifikan antar indikator mengingat angka ini sudah berada diatas nilai 0,5. Begitu juga dengan bartlett's test of sphericity yang mempunyai nilai 8026.947 dengan nilai signifikannya sebesar 0,000 yang artinya bahwa faktor pembentuk variabel ini sudah baik untuk dianalisis uji lanjut.

\section{Tabel 1 - KMO dan Bartlett's test}

\begin{tabular}{|r|r|}
\hline $\begin{array}{r}\text { Kaiser-Meyer-Olkin Measure of } \\
\text { Sampling Adequacy. }\end{array}$ & .927 \\
\hline $\begin{array}{r}\text { Bartlett's Test of } \\
\text { SphericityApprox. Chi-Square }\end{array}$ & 8026.947 \\
\hline $\mathrm{df}$ & 595 \\
\hline Sig & .000 \\
\hline
\end{tabular}

2. Anti-Image Matrices

Setelah terpenuhi syarat pada uji KMO dan bartlett's test of sphericity, langkah selanjutnya 
adalah melihat indikator-indikator mana yang layak untuk analisis faktor. Prosedurnya jika nilai $\mathrm{MSA} \geq 0,5$ maka indikator atau variabel tersebut layak untuk digunakan untuk analisis faktor.

\section{Communalities}

Communalities merupakan nilai yang menunjukkan kontribusi variabel tersebut terhadap faktor yang terbentuk. Communalities pada dasarnya adalah jumlah varian (dalam persentase). Pada variabel 1 (Tabel 2) angkanya adalah 0,659. Hal ini berarti sekitar 65,9\% varian dari variabel 1 bisa dijelaskan oleh faktor yang terbentuk. Demikian juga untuk variabel selanjutnya, dengan ketentuan bahwa semakin besar communalities sebuah variabel, maka semakin erat hubungannya dengan faktor yang terbentuk.

Tabel 2 - Communalities

\begin{tabular}{|c|c|c|c|}
\hline Variabel & Ekstraction & Variabel & Ekstraction \\
\hline VAR1 & .659 & VAR19 & .717 \\
\hline VAR2 & .595 & VAR20 & .500 \\
\hline VAR3 & .642 & VAR21 & .598 \\
\hline VAR4 & .663 & VAR22 & .722 \\
\hline VAR5 & .507 & VAR23 & .675 \\
\hline VAR6 & .603 & VAR24 & .635 \\
\hline VAR7 & .629 & VAR25 & .534 \\
\hline VAR8 & .755 & VAR26 & .599 \\
\hline VAR9 & .806 & VAR27 & .799 \\
\hline VAR10 & .424 & VAR28 & .804 \\
\hline VAR11 & .674 & VAR29 & .617 \\
\hline VAR12 & .715 & VAR30 & .706 \\
\hline VAR13 & .727 & VAR31 & .658 \\
\hline VAR14 & .620 & VAR32 & .674 \\
\hline VAR15 & .593 & VAR33 & .613 \\
\hline VAR16 & .730 & VAR34 & .615 \\
\hline VAR17 & .705 & VAR35 & .597 \\
\hline VAR18 & .627 & & \\
\hline & & & \\
\hline
\end{tabular}

\section{Total Variance Explained}

Berdasarkan nilai initial eigenvalues yang diperoleh maka faktor yang terbentuk sebanyak 7 faktor, dengan masing-masing mempunyai nilai eigenvalues 12,521, 2,886, 2,153, 1,503, 1,424, 1,231, 1,019. Sesuai jumlah faktor yang terbentuk, selanjutnya dapat dijelaskan oleh masing-masing faktor maupun oleh keseluruhan faktor.

\section{Rotasi Faktor}

Pada penelitian ini menggunakan metode rotasi varimax. Tujuan rotasi faktor berusaha meminimumkan banyaknya variabel dengan muatan tinggi (high loading) pada satu faktor, dengan demikian memudahkan pembuatan interpretasi mengenai faktor karena variabel yang masuk dalam faktor tertentu dapat terlihat dengan jelas.

Dari tabel 4 terlihat jelas variabel mana yang masuk atau berkorelasi kuat dengan faktor 1 , faktor 2, factor 3, faktor 4, faktor 5, faktor 6 , ataupun faktor 7. Faktor-faktor inilah yang menentukan kepuasan mahasiswa terhadap pelayanan UNSRAT.

1. Faktor 1 terdiri dari variabel $6,11,12,16,17$, 22, 23, 24, 25.

2. Faktor 2 terdiri dari variabel 26, 27, 28, 29, 32 .
3. Faktor 3 terdiri dari variabel 10, 14, 15, 18, 19, 20, 21.

4. Faktor 4 terdiri dari variabel 1, 2, 3, 4, 5 .

5. Faktor 5 terdiri dari variabel $7,8,9,13$.

6. Faktor 6 terdiri dari variabel 33, 34, 35.

7. Faktor 7 terdiri dari variabel 30 dan 31.

6. Interpretasi Faktor

Diperoleh 7 faktor yang dapat mewakili ke-35 variabel yang dianalisis, yaitu :

a. Faktor pertama adalah kepastian memberikan bobot kontribusi sebesar 35,773\%.

b. Faktor kedua adalah berwujud memberikan bobot kontribusi sebesar 8,246\%.

c. Faktor ketiga adalah keresponsivan memberikan bobot kontribusi sebesar $6,150 \%$.

d. Faktor keempat adalah keandalan memberikan bobot kontribusi sebesar 4,294\%.

e. Faktor kelima adalah empati memberikan bobot kontribusi sebesar 4,068\%.

f. Faktor keenam adalah fasilitas pendukung memberikan bobot kontribusi sebesar 3,518\%. 
g. Faktor ketujuh adalah fasilitas perpustakaan $2,913 \%$. memberikan bobot kontribusi sebesar

Tabel 3 - Total variable explained

\begin{tabular}{|c|c|c|c|}
\hline \multirow{2}{*}{ Component } & \multicolumn{3}{|c|}{ Initial Eigenvalues } \\
\hline & Total & $\%$ of Variance & Cumulative \% \\
\hline 1 & 12.521 & 35.773 & 35.773 \\
\hline 2 & 2.886 & 8.246 & 44.019 \\
\hline 3 & 2.153 & 6.150 & 50.169 \\
\hline 4 & 1.503 & 4.294 & 54.463 \\
\hline 5 & 1.424 & 4.068 & 58.531 \\
\hline 6 & 1.231 & 3.518 & 62.049 \\
\hline 7 & 1.019 & 2.913 & 64.962 \\
\hline 8 & .890 & 2.543 & 67.505 \\
\hline 9 & .845 & 2.414 & 69.919 \\
\hline 10 & .760 & 2.170 & 72.089 \\
\hline 11 & .732 & 2.090 & 74.179 \\
\hline 12 & .665 & 1.899 & 76.078 \\
\hline 13 & .643 & 1.837 & 77.915 \\
\hline 14 & .608 & 1.736 & 79.651 \\
\hline 15 & .581 & 1.659 & 81.311 \\
\hline 16 & .527 & 1.506 & 82.817 \\
\hline 17 & .508 & 1.451 & 84.267 \\
\hline 18 & .492 & 1.405 & 85.672 \\
\hline 19 & .466 & 1.332 & 87.004 \\
\hline 20 & .451 & 1.289 & 88.293 \\
\hline 21 & .414 & 1.184 & 89.477 \\
\hline 22 & .406 & 1.161 & 90.638 \\
\hline 23 & .374 & 1.067 & 91.705 \\
\hline 24 & .357 & 1.020 & 92.725 \\
\hline 25 & .326 & .932 & 93.657 \\
\hline 26 & .298 & .851 & 94.507 \\
\hline 27 & .278 & .794 & 95.301 \\
\hline 28 & .267 & .762 & 96.063 \\
\hline 29 & .244 & .696 & 96.759 \\
\hline 30 & .236 & .674 & 97.433 \\
\hline 31 & .212 & .606 & 98.040 \\
\hline 32 & .203 & .581 & 98.620 \\
\hline 33 & .190 & .543 & 99.163 \\
\hline 34 & .167 & .477 & 99.640 \\
\hline 35 & .126 & .360 & 100.000 \\
\hline
\end{tabular}

Extraction Method: Principal Component Analysis.

\section{Conclusion}

Kesimpulan dalam penelitian ini:

1) Mahasiswa sudah cukup puas dengan pelayanan yang diberikan oleh Universitas Sam Ratulangi dengan tingkat kepuasan 64,9\%.

2) Dari hasil penelitian diperoleh 7 faktor baru penentu kepuasan mahasiswa hasil ekstrasi dari analisis faktor yaitu faktor kepastian, berwujud, keresponsivan, keandalan, empati, fasilitas pendukung, dan fasilitas perpustakaan. Faktor kepastian merupakan faktor dominan berpengaruh terhadap kepuasan mahasiswa karena mempunyai bobot kontribusi terbesar dari faktor yang lain yaitu $35,773 \%$. Indikator-indikator pada faktor pertama inilah yang dominan mempengaruhi kepuasan mahasiswa.

3) Indikator-indikator penyusun faktor kepastian adalah karyawan sopan dalam melayani mahasiswa, seluruh karyawan dengan senang hati dan sabar melayani kebutuhan mahasiswa, seluruh karyawan bersedia membantu kesulitan yang di hadapi oleh mahasiswa, seluruh karyawan bersedia meluangkan waktu untuk menanggapi permintaan mahasiswa dengan cepat, karyawan menguasai informasi seputar pelayanan mahasiswa, karyawan memberikan informasi dengan jelas dan terinci tentang pelayanan yang akan di berikan, bagian administrasi memiliki jam kerja yang sesuai dengan kebutuhan mahasiswa, bagian administrasi memiliki jam kerja yang sesuai dengan kebutuhan mahasiswa, fakultas anda 
memiliki bagian administrasi yang cermat dan kooperatif, dan dosen selalu mengutamakan kepentingan mahasiswa.

\section{References}

Pidekso, A. 2009. Panduan Praktis SPSS 17 Untuk Pengolahan Data Statistik. Andi. Yogyakarta. 